\title{
Treatment of Acute Necrotising Pancreatitis and Its Complications: The Surgeon's Perspective
}

\author{
Luca Dani $^{a}$ Giulia Carbonaro ${ }^{a}$ Fabrizio Natta ${ }^{a}$ Giuseppe Cavuoti ${ }^{a}$ \\ Giacomo Paolo Vaudano $^{b}$ Andrea Boghi $^{c}$ Federico Festa ${ }^{a}$ \\ Luca Cestino $^{a}$ Stefania Soncini ${ }^{a}$ Francesco Quaglino ${ }^{a}$

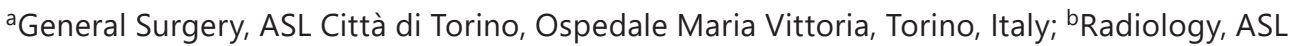 \\ Città di Torino, Ospedale San Giovanni Bosco, Torino, Italy; ${ }^{c}$ Neuroradiology, ASL Città di \\ Torino, Ospedale San Giovanni Bosco, Torino, Italy
}

\section{Keywords}

Pancreatitis · Surgery $\cdot$ Bleeding $\cdot$ Conservative treatment

\begin{abstract}
Acute necrotising pancreatitis (ANP) is associated with high complication and mortality rates. It is still difficult for the surgeon to choose and schedule the most appropriate treatment. Compared to the past, the current minimally invasive "step-up" approach enables better outcomes in terms of morbidity/mortality, notwithstanding long periods of hospitalisation, and above all ensures better levels of residual pancreatic function. We hereby report the case of a patient hospitalised in our division for approximately 4 months with a diagnosis of ANP complicated by infection and late bleeding, handled with a sequential approach.

\section{Introduction}

Pancreatic necrosis is an infrequent but serious complication of acute pancreatitis, with a mortality rate ranging from $15 \%$ to $30 \%$, which increases with the onset of complications such as infection or multi-organ failure [1]. Pancreatic necrosis is diagnosed through a CT scan, and staging is performed according to the Balthazar index [2, 3] (Table 1). This event occurs in approximately $5-10 \%$ of patients with acute pancreatitis and can affect pancreatic parenchyma, peripancreatic tissues, or both. The complications of ANP consist in the dissemination of the collection within the peritoneal or retroperitoneal cavity, haemorrhage, and compressive symptoms on the duodenum, colon, and portal vein. 
Table 1. Balthazar CT severity index

\begin{tabular}{lll}
\hline CT grade & Grade score & Definition \\
\hline A & 0 & Normal pancreas \\
B & 1 & Focal or diffuse enlargement/heterogeneity \\
C & 2 & Intrinsic abnormality and haziness in peripancreatic fat \\
D & 3 & Single, ill-defined fluid collection \\
E & 4 & Two or more ill-defined collections or pancreatic/peripancreatic gas \\
gland necrosis, \% & necrosis score & definition \\
None & 0 & Uniform pancreatic enhancement \\
$<30$ & 2 & Non-enhancement of region of gland equivalent in size to the \\
& & pancreatic head \\
$30-50$ & 4 & Non-enhancement of $30 \%-50 \%$ of the gland \\
$>50$ & 6 & Non-enhancement of over $50 \%$ of the gland
\end{tabular}

Fig. 1. Abdominal CT scan showing the necrosis of the pancreatic tissue.

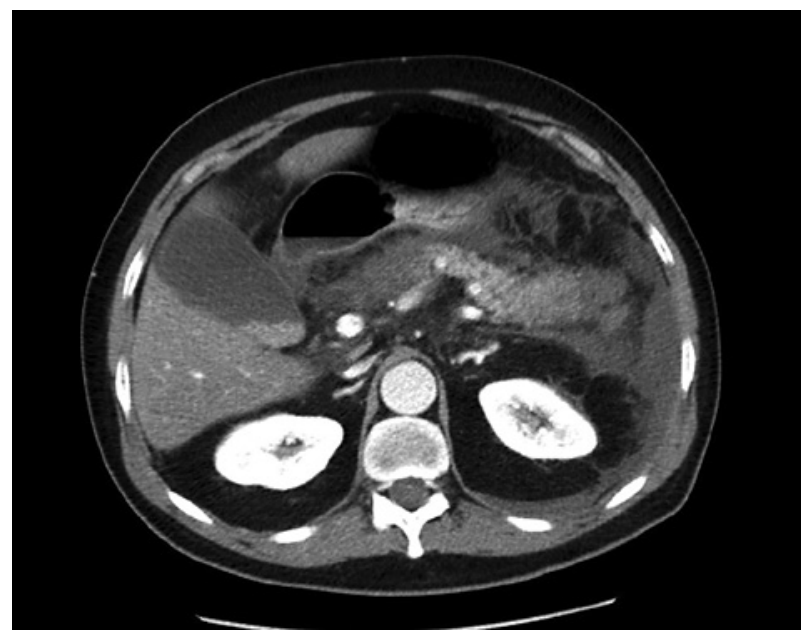

In the past, the only weapon available against ANP was surgical necrosectomy, with complication and mortality rates up to $40 \%$ [4]. Recently, a less invasive method, called the "step-up approach," has been adopted to treat both necrosis and complications [5], including haemorrhage, using interventional radiology techniques, minimally invasive surgery, and advanced life support. Although this approach requires prolonged hospitalisation, it presents lower morbidity and mortality rates and above all ensures better results in terms of pancreatic function. Please find below a case observed at our operating unit, complicated by infection and late bleeding of a branch of the splenic artery.

\section{Case Report}

A 66-year-old male patient arrived at the ER with abdominal pain: the relevant tests led to the diagnosis of ANP and multi-organ failure, resulting in admission to the ICU in order for the patient to receive supportive care, broad-spectrum antibiotics, and NIV. The score according to Ranson's criteria was 6, correlated with a mortality of 40\%, and the abdominal CT scan showed necrosis of the pancreatic tissue with perihepatic and perisplenic effusion (shown in Fig. 1). 
Fig. 2. Abdominal CT scan showing the percutaneous drainage of peripancreatic collection.

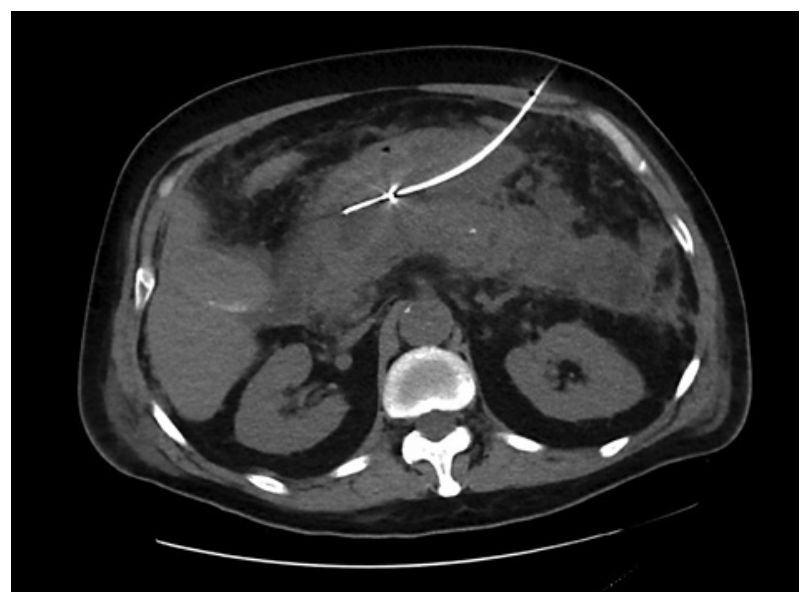

Subsequent to progressive clinical improvement, 13 days later, the patient was transferred to the emergency department, and CT scans showed a progressive single organisation of the collection in the omental bursa. On the 16th day after admission, as the septic status did not respond to antibiotics and in view of the CT scans, percutaneous drainage was performed (shown in Fig. 2); initially, the patient improved, but given the persistence of undrained collections and fever, percutaneous drainage was repeated after 7 days. The patient never exhibited symptoms or clinical signs of abdominal compartment syndrome, with IAP always below $15 \mathrm{~mm} \mathrm{Hg}$.

On the 44th day, in the absence of any clinical improvements and as the drainages were unsuccessful, the multidisciplinary team decided to perform a surgical laparotomic drainage. Midline laparotomy was performed with cautious access to the omental bursa, and the abscess cavity was debrided and drained. Last, 2 additional drains were placed in order to ensure post-surgery cleansing.

After 15 days since the operation (59 days after admission to the hospital) subsequent to acute anaemia ( $\mathrm{Hb}$ 6.6) with stable haemodynamics, a CT showed bleeding in the vicinity of a collateral branch of the splenic artery. On the same date, arteriography showed the presence of a pseudoaneurysm in an inferior polar branch of the splenic artery which was occluded by coil embolization (shown by the arrow in Fig. 3).

The subsequent course was characterised by multiple infections from multi-resistant germs for which antibiotic therapy was patient tailored on the basis of the antibiogram. Over the entire hospital stay, cleansing was performed through the drains, which always remained patent, ensuring the discharge of necrotic strands and pus. Subsequent to clinical improvement, in the absence of signs of inflammation and secretions from the drains, the last abdominal CT scan was performed on the 81st day after surgery (125th after admission), confirming that the clinical picture was almost resolved. The drainage was removed, and on the 85th day (129th after admission), the patient was discharged. The endocrine and exocrine pancreatic function always remained preserved. After 3 months, the patient underwent open cholecystectomy with regular outcome.

\section{Discussion}

The traditional approach to ANP was surgical necrosectomy. This invasive approach is associated with a high percentage of complications (34-95\%) and death (11-39\%) with a very high risk of pancreatic failure [6,7]. The "step-up" approach $[8,9]$ is currently considered 
Fig. 3. Arteriography showing the embolization of the pseudoaneurysm (indicated by the arrow) in an inferior polar branch of the splenic artery.

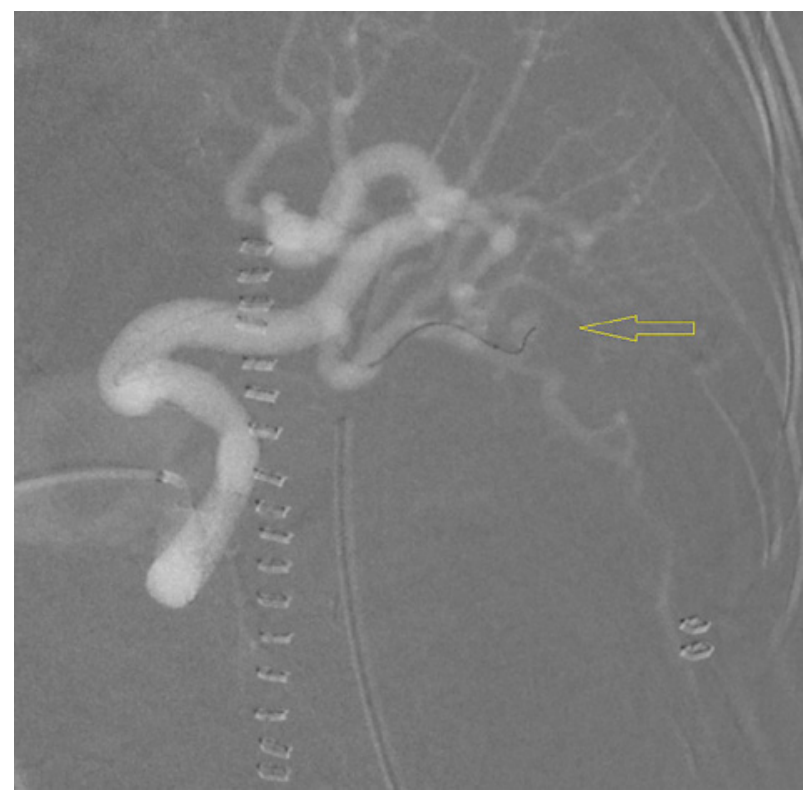

the gold standard in the management of ANP. It consists in a multidisciplinary assessment and the use of techniques that are as minimally invasive and as progressive as possible, including percutaneous drainage, endoscopic drainage, and retroperitoneal necrosectomy and, in selected cases, surgical necrosectomy. Percutaneous drainage can be used as a first approach, possibly followed by endoscopic drainage or video-assisted necrosectomy. However, even when the "step-up" method is adopted, it may still be necessary to resort to surgical necrosectomy without any delay so as not to risk deteriorating the clinical outcome $[10,11]$. Open surgery has precise indications. The onset of compartment syndrome, bleeding which cannot be controlled with interventional radiology techniques, intestinal perforation, or intestinal or biliary obstruction resulting from extrinsic compression $[12,13]$ remain indications for open surgery.

A less obvious indication is the failure of the minimally invasive techniques previously employed with persistence of sepsis. In our case, we decided to implement the "step-up" approach by treating the necrosis infection with percutaneous drainage. Nevertheless, on the 44th day, it was necessary to resort to surgical debridement as the percutaneous drains could not discharge the necrotic material, and the patient presented with signs of worsening sepsis with fever peaks despite the personalised antibiotic therapy.

Keeping in view of a "minimally invasive" approach, the surgery consisted in positioning a drain in the emplacement of the previous percutaneous drains which enabled the debridement of the intracavitary septa, as well as other communicating drains in order to ensure constant washing of the material. The patient's modest but progressive clinical improvement with this procedure avoided the deployment of more invasive techniques such as laparostomy.

The bleeding complication should also be handled, when possible, using non-invasive interventional radiology techniques, limiting surgical treatment in the operating theatre to cases of failure of such procedures [12]. The erosion of the vessels adjacent to the collections or the formation of false aneurysms can arise as a late complication of ANP and even occur after the drainage of the necrotic collection. Consistent with the above, the supervening haemorrhagic complication was also treated through interventional radiology by controlling the bleeding.

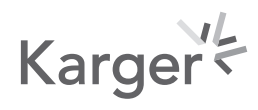


A success rate exceeding $50 \%$ has been described in the literature for percutaneous drainage as the only treatment [14]. Similarly, endoscopic procedures achieve a satisfactory efficacy rate, up to $75 \%-95 \%$ in some studies [15]. However, prolonged and ineffective treatment with non-invasive techniques and subsequent conversion to surgery can result in an increased mortality rate $[9,10]$. To this day, it has not been possible to pinpoint prognostic factors which can help predict the success of non-invasive techniques, and it is difficult to identify beforehand those patients who will benefit poorly from non-invasive treatments and who would have a better outcome if they underwent surgical necrosectomy as the first step. Certainly, the content of the collection and the number and position of the collections can suggest whether to opt for a percutaneous approach. Therefore, the choice of the initial intervention depends on several factors: the time elapsed since the onset of symptoms, location, extent, and nature of the necrotic collections. Nonetheless, in our opinion, upon treating these very complicated patients, ongoing multidisciplinary assessment is fundamental, with the possibility of implementing all the techniques available, limiting surgical treatment to the cases described above.

The "step-up" approach must be considered the standard for the treatment of ANP. Where possible, it is advisable to apply interventional radiology and minimally invasive surgery techniques even in the event of a bleeding complication. Although this method requires prolonged hospitalisation, it reduces morbidity and mortality risks and ensures better residual pancreatic function.

\section{Acknowledgment}

This manuscript does not include any non-author contributors to acknowledge.

\section{Statement of Ethics}

Ethical approval for publication of a case report is not required in accordance with local and national guidelines. Written informed consent was obtained from the patient for publication of this case report and any accompanying images.

\section{Conflict of Interest Statement}

The authors have no conflicts of interest to declare.

\section{Funding Sources}

This manuscript did not receive any funding.

\section{Author Contributions}

F.Q., F.N., G.C., G.P.V., A.B., and S.S. are the physicians directly involved in the case. L.D. and G.C. wrote the manuscript in consultation with F.F. and L.C. F.Q. supervised the project. All authors provided feedback and contributed to the final manuscript. 


\section{References}

1 Kokosis G, Perez A, Pappas TN. Surgical management of necrotizing pancreatitis: an overview. World J Gastroenterol. 2014 Nov 21;20(43):16106-12.

2 Balthazar EJ, Robinson DL, Megibow AJ, Ranson JH. Acute pancreatitis: value of CT in establishing prognosis. Radiology. 1990 Feb;174(2):331-6.

3 Leung TK, Lee CM, Lin SY, Chen HC, Wang HJ, Shen LK, et al. Balthazar computed tomography severity index is superior to Ranson criteria and APACHE II scoring system in predicting acute pancreatitis outcome. World J Gastroenterol. 2005 Oct 14;11(38):6049-52.

4 Wroński M, Cebulski W, Witkowski B, Jankowski M, Kluciński A, Krasnodębski IW, et al. Comparison between minimally invasive and open surgical treatment in necrotizing pancreatitis. J Surg Res. 2017 Apr;210:22-31.

5 van Santvoort HC, Besselink MG, Bakker OJ, Hofker HS, Boermeester MA, Dejong CH, et al. A step-up approach or open necrosectomy for necrotizing pancreatitis. N Engl J Med. 2010 Apr 22;362(16):1491-502.

6 Howard TJ, Patel JB, Zyromski N, Sandrasegaran K, Yu J, Nakeeb A, et al. Declining morbidity and mortality rates in management of pancreatic necrosis. J Gastrointest Surg. 2007 Jan;11(1):43-9.

7 Rau B, Bothe A, Beger HG. Surgical treatment of necrotizing pancreatitis by necrosectomy and closed lavage: changing patient characteristics and outcome in a 19-year, single-center series. Surgery. 2005 Jul;138(1): 28-39.

8 van Santvoort HC, Besselink MG, Horvath KD, Sinanan MN, Bollen TL, van Ramshorst B, et al. Videoscopic assisted retroperitoneal debridement in infected necrotizing pancreatitis. Dutch acute pancreatis study group. HPB. 2007;9(2):156-9.

9 Besselink MG, van Santvoort HC, Nieuwenhuijs VB, Boermeester MA, Bollen TL, Buskens E, et al. Minimally invasive "step-up approach" versus maximal necrosectomy in patients with acute necrotising pancreatitis (PANTER trial): design and rationale of a randomised controlled multicenter trial (ISRCTN13975868). Dutch acute pancreatitis study group. BMC Surg. 2006 Apr 11;6:6.

10 Gomatos IP, Halloran CM, Ghaneh P, Raraty MG, Polydoros F, Evans JC, et al. Outcomes from minimal access retroperitoneal and open pancreatic necrosectomy in 394 patients with necrotizing pancreatitis. Ann Surg. 2016 May;263(5):992-1001.

11 Babu RY, Gupta R, Kang M, Bhasin DK, Rana SS, Singh R, et al. Predictors of surgery in patients with severe acute pancreatitis managed by the step-up approach. Ann Surg. 2013 Apr;257(4):737-50.

12 Głuszek S, Nawacki Ł, Matykiewicz J, Kot M, Kuchinka J. Severe vascular complications of acute pancreatitis. Pol Przegl Chir. 2015 Oct;87(10):485-90.

13 Kirkpatrick AW, Roberts DJ, De Waele J, Jaeschke R, Malbrain ML, De Keulenaer B, et al. Intra-abdominal hypertension and the abdominal compartment syndrome: updated consensus definitions and clinical practice guidelines from the World Society of the Abdominal Compartment Syndrome. Intensive Care Med. 2013 Jul; 39(7):1190-206.

14 van Baal MC, van Santvoort HC, Bollen TL, Bakker OJ, Besselink MG, Gooszen HG. Systematic review of percutaneous catheter drainage as primary treatment for necrotizing pancreatitis. Br J Surg. 2011 Jan;98(1):18-27.

15 Seifert H, Biermer M, Schmitt W, Jürgensen C, Will U, Gerlach R, et al. Transluminal endoscopic necrosectomy after acute pancreatitis: a multicentre study with long-term follow-up (the GEPARD Study). Gut. 2009 Sep; 58(9):1260-6. 